7. Reprod. Fert. (1972) 29, 133-136

\title{
A SEQUENTIAL HISTOLOGICAL STUDY OF THE POST-PARTUM BOVINE UTERUS
}

\author{
L. F. ARCHBALD, ${ }^{*}$ R. H. SCHULTZ*, M. L. FAHNING, ${ }^{*}$ H. J. KURTZ $\dagger$ \\ AND R. ZEMJANIS* \\ *Department of Veterinary Obstetrics and Gynecology, and \\ $\dagger$ Department of Veterinary Pathology and Parasitology, University of Minnesota, \\ St Paul, Minnesota 55101, U.S.A.
}

(Received 22nd October 1971, accepted 5th November 1971)

Eighteen pregnant cows were individually housed and allowed to calve normally. None of the cows retained fetal membranes. Tissues were obtained for study on Days 1, 3, 5, 7, 11, 15, 19, 23, 27, 31, 45 and 60 post partum. Because the exact time of calving of each animal was not known, the term 'Day l' represented an approximated period of $24 \mathrm{hr}$ beginning from the time of observation of the calf with its dam in the maternity stall.

Following exposure of the internal genitalia as described by Schultz, Fahning \& Graham (1966), caruncular and intercaruncular uterine samples were obtained from an area at the base of the uterine horn by an in-vivo serial surgical technique (Archbald, 1969). Uterine samples were also obtained by percervical biopsy (Skjerven, 1956) and at necropsy. All samples were fixed in 10\% phosphate-buffered formalin for approximately 5 days. After trimming, they were embedded in paraffin wax, and sections cut at $6 \mu \mathrm{m}$ were stained with haematoxylin and eosin as described by Humason (1967). Table 1 shows the chronological sampling sequence for each cow, and Table 2 shows the total number of samples obtained on each day post partum and the method of sampling.

The histological features of tissue sections from all the animals studied were similar. Sections of caruncular tissue revealed the presence of numerous remnants of chorioallantoic cells in maternal crypts on Day 1 . These remnants underwent necrosis and mineralization, and were either phagocytized by macrophages observed in the area or expelled with the lochia. Neither necrotic nor mineralized chorioallantoic cells were observed in the caruncle after Day 11 post partum. Gier \& Marion (1968) reported the presence of chorioallantoic cells in the lumen of maternal caruncular crypts at Day 2 post partum. It therefore appears that detachment of terminal portions of chorioallantoic villi in maternal crypts and shrinking of chorioallantoic villi and dilatation of maternal caruncular crypts (Roberts, 1956) probably play a major rôle in separation of fetal and maternal placentae.

Progressive degenerative vascular changes were observed in the mediumsized and smaller arteries of the caruncular stratum compactum from Days 1 to 19. These changes consisted of hydropic degeneration of the cytoplasm and pycnosis of the smooth muscle cells of the tunica media and fibrinoid necrosis of Approved as Scientific Journal Series Paper No. 7573, Minnesota Agricultural Experiment Station. 


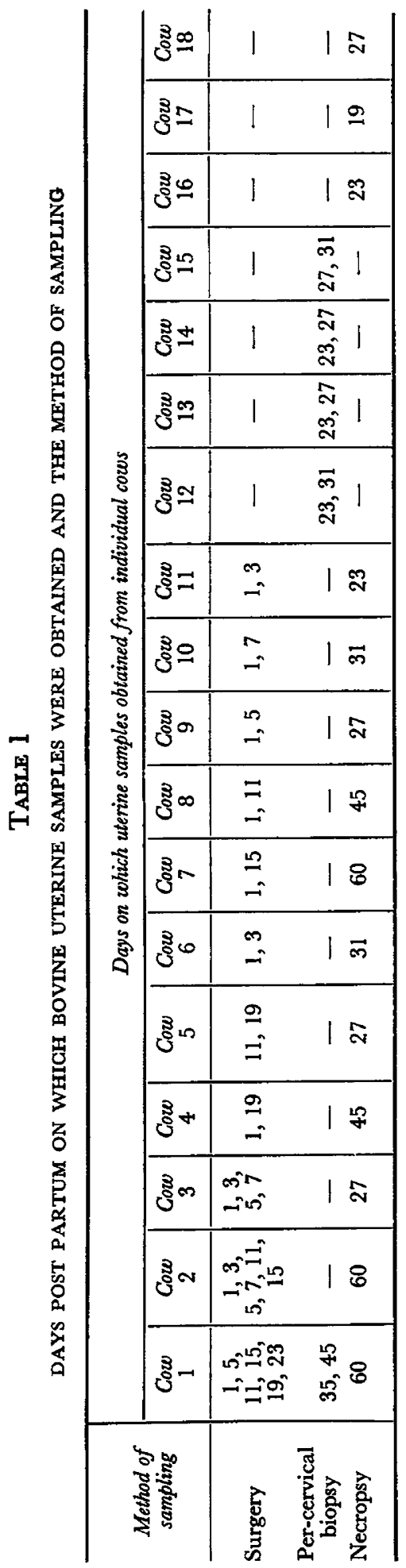

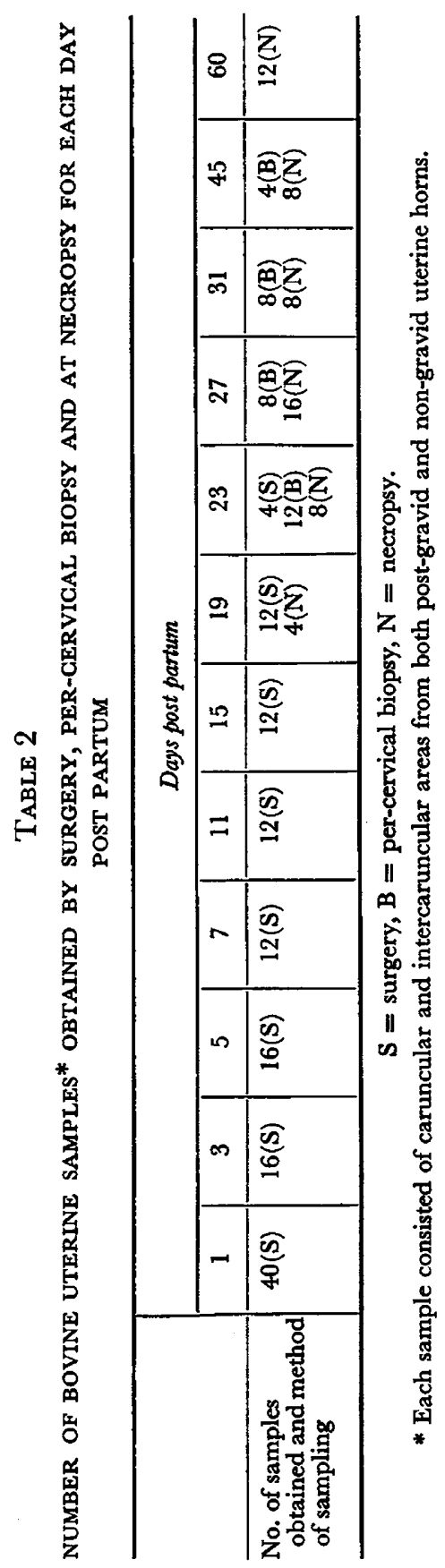


the tunica media. Vascular changes were confined to the tunica media and luminal patency was a constant finding. The aetiology of these vascular changes is open to speculation. Progressive necrosis and sloughing of the superficial areas of the caruncle was concomitant with these vascular changes. The latter were first observed on Day 1 and necrotic changes in the stratum compactum were first observed on Day 5 post partum. Sloughing of the superficial layer of the caruncle became noticeable around Days 6 and 7, and the stratum compactum was greatly reduced in size, almost to the level of the intercaruncular area by Day 15. Gier \& Marion (1968) reported necrosis and cellular disorganization of the caruncle on Day 5, the necrosis beginning on Day 2 post partum. Wagner \& Hansel (1969) observed some exudate on the uterine mucosal surface on Day 7, and reported that sloughing of the caruncular surface appeared to begin at a point just basal to the maternal crypts. The sequence of events in the involution of the maternal caruncle appeared to be the following: degenerative vascular changes, peripheral ischaemia, necrosis and sloughing. Rasbech (1950) suggested that involution involved the disappearance of the caruncular stalk through vasoconstriction with subsequent dissolution of the superficial layer of the uterine caruncle. In this study, vasoconstriction in the caruncular stalk was not readily apparent.

Focal areas of epithelial cells were observed over the caruncular surface on Day 1. These cells were pleomorphic and contained large, hyperchromatic nuclei and granular cytoplasm. Epithelium covering the surface of the caruncle was also observed on Days 3 and 5 . However, because of necrosis of the stratum compactum between Days 5 and 6 , the superficial layer of the caruncle with its epithelium was sloughed into the uterine lumen. Cuboidal-type epithelial cells with large, hyperchromatic nuclei and granular cytoplasm were present over focal areas of the caruncle by Day 15, and the entire caruncular surface was covered by an epithelial layer by Day 19. According to Roberts (1956), the surface of the bovine caruncle is devoid of epithelium at the time of parturition. Rasbech (1950) reported replacement of caruncular epithelium at about Day 20, while Gier \& Marion (1968) found that even under the most favourable conditions, the caruncular surface was not covered by epithelium before Day 25. Wagner \& Hansel (1969) observed that by Days 12 to 14 post partum, regeneration of the caruncular epithelium was beginning and the caruncular surface was covered with an epithelial layer in the majority of animals killed on Day 30 post partum.

Both degenerated and regenerated epithelial cells were observed in the intercaruncular epithelium on Day 1. The degenerated cells were confined to the basal areas of the epithelium and were characterized by pycnosis and vacuolation of the cytoplasm. The regenerated cells were interspersed among the degenerated epithelial cells and were characterized by large, hyperchromatic nuclei and granular cytoplasm. The two processes of epithelial cell degeneration and regeneration continued simultaneously until Day 15, at which time no degenerative epithelial cells were observed. The regenerated cells seemed to originate from the basal area of the endometrial epithelium. Replacement of endometrial epithelium by epithelium of the uterine endometrial glands, as described by Gier \& Marion (1968), was not observed in this 
study. At no time during uterine involution was the intercaruncular area devoid of an epithelial layer. This was in contrast to reports by other workers. Gier \& Marion (1968) reported that regeneration of uterine endometrial epithelium began almost immediately after parturition in areas not seriously damaged during parturition, and the entire intercaruncular area was covered by epithelium by Day 8 . Rasbech (1950), Gier \& Marion (1968) and Wagner \& Hansel (1969) found that the uterine endometrial epithelium was re-established in normal cows by Day 30 post partum.

The epithelial cells of the uterine endometrial glands exhibited a pattern of simultaneous degeneration and regeneration similar to that observed in the intercaruncular area. Similar changes in the endometrial glands were observed in necropsy material from a cow estimated to be approximately $8 \frac{1}{2}$ months pregnant but these changes were not observed in the intercaruncular endometrial epithelium. Embryologically, the uterine endometrial glands arise as invaginations of the uterine surface epithelium. It is not surprising, therefore, that the epithelia of the uterine glands and endometrium exhibited similar morphological features, though it is not known why degenerative changes in the epithelium of the endometrial glands ceased before those in the endometrial epithelium. Degenerative changes in the epithelium of the endometrial glands without similar changes in the uterine surface epithelium were also observed in the pre-partum cow. This suggests that there may be a preferential time reponse of these epithelial layers to the sex hormones.

The histological changes observed in the myometrium consisted of granular degeneration of the sarcoplasm, vacuolation of the muscle cell and atrophy of the nucleus. The initial stages of this process were observed on Day 3 and the nuclei of the muscle fibres appeared atrophic on Day 27. By Day 31, the fibres appeared normal and the entire myometrium was greatly reduced in size compared to that in the early post-partum period. Necrosis of the muscle fibres was not observed during post-partum myometrial regression.

This work was supported by funds from the Minnesota Agricultural Experiment Station budget and the Hill Family Foundation, for which gratitude is expressed. This data formed the basis of a thesis submitted by the senior author to the University of Minnesota in partial fulfilment of the requirements for an M.S. degree.

\section{REFERENCES}

Archbald, L. F. (1969) The histologic study of the post-partum bovine uterus. M.S. thesis, University of Minnesota.

GIER, H. T. \& MARION, G. B. (1968) Uterus of the cow after parturition: involutional changes. Am. $\mathcal{F}$. vet. Res. 29, 83.

Humason, G. L. (1967) Animal tissue techniques, 2nd edn, p. 142. Freeman, San Francisco.

Rasbech, N. O. (1950) The normal involution of the uterus of the cow. Nord. VetMed. 2, 655.

Roberts, S. J. (1956) Veterinary obstetrics and genital diseases, pp. 36, 122. Published by author, Ithaca, New York.

Schultz, R. H., Fahning, M. L. \& Graham, E. F. (1966) A surgical technique for exposure of the bovine internal genitalia. Vet. Rec. 78, 91 .

SkJerven, O. (1956) Endometrial biopsy studies in reproductively normal cattle. Acta endocr., Copenh. 22, 1.

WAGNER, W. C. \& Hansel, W. (1969) Reproductive physiology of the post-partum cow. I. Clinical and histological findings. F. Reprod. Fert. 18, 493. 